\title{
How to deliver aerosolized medications through high flow nasal cannula safely and effectively in the era of COVID-19 and beyond: A narrative review
}

\author{
Arzu Ari, PhD, RRT, PT, CPFT, FAARC, FCCP ${ }^{1}$, Gerald B. Moody, BSRC, RRT-NPS ${ }^{2}$
}

\begin{abstract}
A Ari, GB Moody. How to deliver aerosolized medications through high flow nasal cannula safely and effectively in the era of COVID-19 and beyond: A narrative review. Can J Respir Ther 2021;57:22-25. doi: 10.29390/cjrt-2020-041.

Background: The treatments of COVID-19 involve some degree of uncertainty. Current evidence also shows mixed findings with regards to bioaerosol dispersion and airborne transmission of COVID-19 during high flow nasal cannula (HFNC) therapy. While coping with this global pandemic created hot debates on the use of HFNC, it is important to bring detached opinions and current evidence to the attention of health care professionals (HCPs) who may need to use HFNC in patients with COVID-19.

Aim: The purpose of this paper is to provide a framework on the selection, placement, and use of nebulizers as well as HFNC prongs, gas flow, and delivery technique via HFNC to help clinicians deliver aerosolized medications through HFNC safely and effectively in the era of COVID-19 and beyond.

Methods: We searched PubMed, Medline, CINAHL, and Science Direct to identify studies on aerosol drug delivery through HFNC using the following keywords: ("aerosols," OR "nebulizers") AND ("high flow nasal cannula" OR "high flow oxygen therapy" OR "HFNC") AND ("COVID-19," OR "SARSCoV-2"). Twenty-eight articles including in vitro studies, randomized clinical trials, scintigraphy studies, review articles, prospective and retrospective research were included in this review.

Discussion and results: It is not clear if the findings of the previous studies on bacterial contamination could be applied to viral transmission because they do not provide data that could be extrapolated to the risk of SARS-CoV-2 transmission. In the face of the unknown risk with the transmission of COVID19 during HFNC therapy, the benefits of HFNC must be weighed against the risk of infection to HCPs and other patients. Due to the limited number of ventilators available in hospitals and the confirmed effectiveness of HFNC in treating hypoxemic respiratory failure, HFNC may prevent early intubation, and prolonged intensive care unit stays in patients with COVID-19.

Conclusion: Clinicians should review the magnitude of this risk based on current evidence and use the suggested strategies of this paper for safe and effective delivery of aerosolized medications through HFNC in the era of COVID-19 and beyond.
\end{abstract}

Key Words: high flow nasal cannula; aerosols; nebulizers; drug delivery; COVID-19; infection control

\section{INTRODUCTION}

As severe acute respiratory syndrome coronavirus-2 (SARS-CoV-2) poses an ever-greater risk to individual and community health worldwide, the number of critically ill patients with COVID-19 who require intensive care increased significantly. Given the rapid spread of SARS-CoV-2 and the limited number of ventilators available in the intensive care units (ICUs), using high flow nasal cannula (HFNC) in patients with hypoxemic respiratory failure has become an integral component of the global response to this pandemic as it may reduce the need for ventilatory support compared with conventional oxygen therapy $[1,2]$. However, there are detached opinions on the use of HFNC in this patient population. Some clinicians do not want to use HFNC for aerosol delivery to patients with COVID-19, because they think that the dispersion of bioaerosol to the environment is high and increased bioaerosol dispersion may lead to a viral transmission. Others believe that the HFNC should be used for the delivery of aerosolized medication in the era of COVID-19 due to its effectiveness in the treatment of hypoxemic respiratory failure. Also, early intubation is considered a high-risk procedure for COVID-19, and prolonged ICU stay is an issue due to the limited number of ventilators available. Therefore, the purpose of this paper is to review detached opinions and provide strategies for the safe and effective delivery of aerosolized medications through HFNC in the era of COVID-19 and beyond.

\section{METHODS}

We searched PubMed, CINAHL, and Science Direct from June 1, 2005 to December 25, 2020, to identify studies on aerosol drug delivery through HFNC. The following keywords were used in the search of relevant publications: ("aerosols," OR "nebulizers") AND ("high flow nasal cannula" OR "high flow oxygen therapy" OR "HFNC") AND ("COVID19," OR "SARS-CoV-2"). Although a total of 77 articles were identified; abstracts, letters to the editor, and studies published in a language other than English were excluded. Twenty-eight articles that are in vitro studies, randomized clinical trials, scintigraphy studies, review articles, prospective and retrospective research were included in this review (Figure 1). Two reviewers independently assessed the eligibility of each paper based on the evidence of exhaled air dispersion and viral transmission with HFNC as well as the presence of recommendations on aerosol drug delivery through HFNC in patients with COVID-19.

\footnotetext{
${ }^{1}$ Department of Respiratory Therapy, Texas State University, Round Rock, TX, USA

${ }^{2}$ Children's Health - Children's Medical Center, Department of Respiratory Care, Dallas, TX, USA

Correspondence: Arzu Ari, Department of Respiratory Care, Texas State University, College of Health Professionals, 200 Bobcat Way, Willow Hall, Suite \# 214, Round Rock, TX, USA. E-mail: arzuari@txstate.edu
}

Published online at https://www.cjrt.ca on 01 March 2021 


\section{FIGURE 1}

Literature search and selection process for this narrative review.

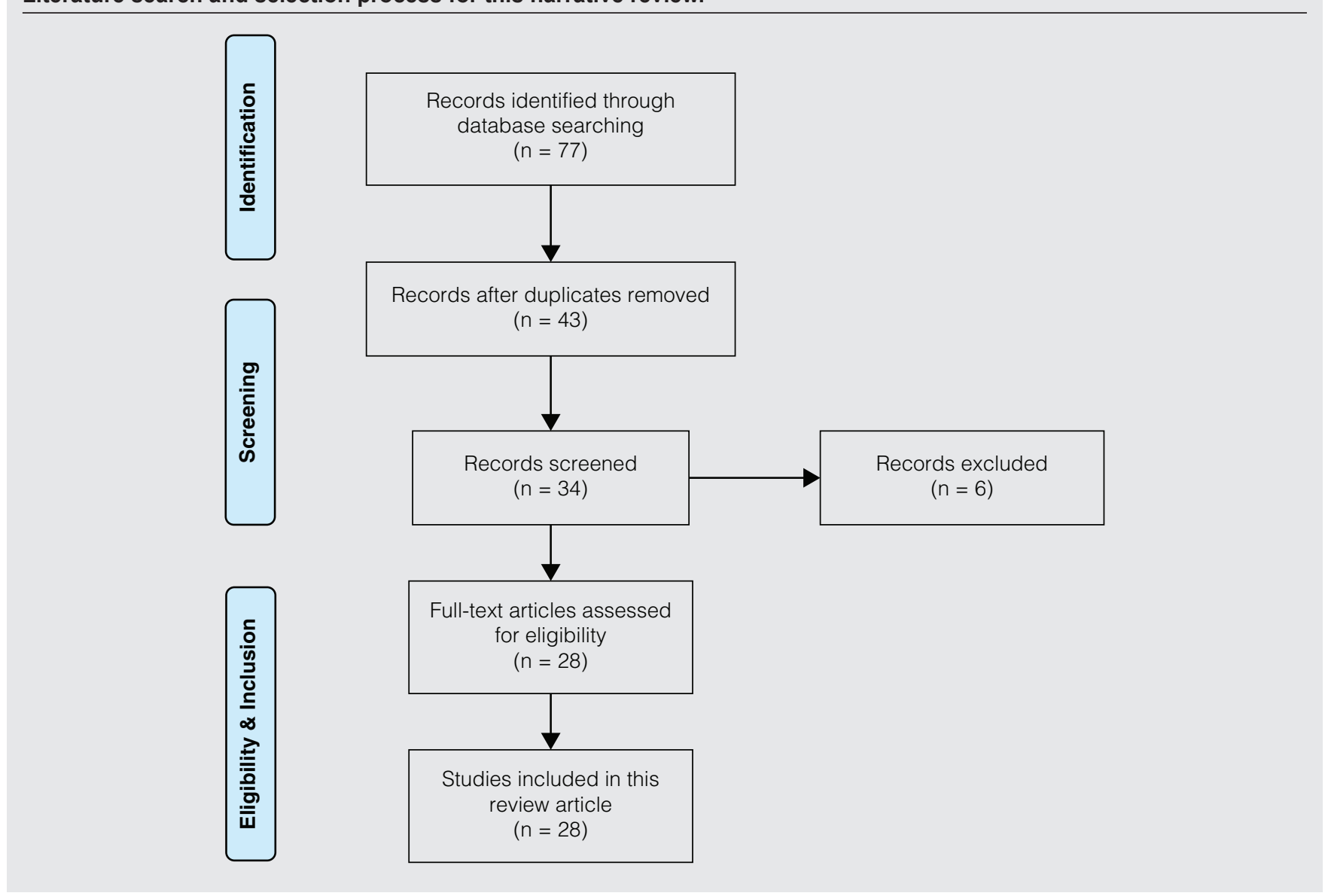

\section{DISCUSSION}

Since one of the main mechanisms of action of HFNC is the washing out of the patient's pharyngeal dead-space, concerns have been raised that the high flows used to flush expired gas from the upper airway of infected patients may increase bioaerosols dispersion into the environment. Additionally, in some patients, concurrent therapy with inhaled medications may be necessary [3-5], and clinicians are concerned about administering medications through HFNC that might exacerbate the aerosolization and spread of infectious particles to health care professionals (HCPs) or other patients.

Using a direct visualization of exhaled smoke dispersion and similar breathing parameters, Hui et al. [6] and Ip et al. [7] measured the maximum dispersion distance of exhaled smoke particles with the HFNC and oxygen mask, respectively. The dispersion distance of particles via HFNC at $60 \mathrm{~L} / \mathrm{min}$ shows a similar risk to a simple oxygen mask at $15 \mathrm{~L} / \mathrm{min}$ [7]. Furthermore, exhaled dispersion distance with the Venturi and nonrebreathing masks was much greater than HFNC [7]. In a clinical study on 19 patients with bacterial pneumonia, Leung et al. [8] compared HFNC at $60 \mathrm{~L} / \mathrm{min}$ with an oxygen mask at $8.6 \mathrm{~L} / \mathrm{min}$ on environmental contamination and bacterial growth measured through patient's room air and settle plates placed at $0.4 \mathrm{~m}$ and $1.6 \mathrm{~m}$ from patients. They reported no significant difference in bacterial growth in the air sample and settling plates between HFNC and oxygen mask at 1, 2 , and 5 days of incubation [8]. A recent in-vitro study also did not show an increase in the potential risk of droplet and contact infection with HFNC [9]. However, SARS-CoV-2 has been shown to survive aerosolization [10], and it is not clear if the findings of these studies on bacterial contamination could be applied to viral transmission, because they do not provide data that could be extrapolated to the risk of SARS-CoV-2 transmission. In the face of the unknown risk with the transmission of COVID-19 during HFNC therapy, the benefits of HFNC must be weighed against the risk of infection to HCPs and other patients.

Currently, there is a limited number of ventilators available in ICUs and early intubation poses a high risk for COVID-19. Due to the confirmed effectiveness, comfort, and convenience of HFNC in the treatment of hypoxemic respiratory failure, HFNC may prevent early intubation and prolonged ICU stay in patients with COVID-19. Therefore, reviewing the magnitude of this risk based on current evidence and developing strategies for safe and effective delivery of aerosolized medications through HFNC is essential on a wide scale within and across health care institutions. Table 1 lists suggestions on how to deliver aerosolized medications through HFNC safely and effectively to patients with COVID-19 [3, 11].

Caregivers were estimated to be exposed to $8.5 \%$ and $3.2 \%$ of the nebulized loading dose during HFNC therapy at $0.8 \mathrm{~m}$ and $2.2 \mathrm{~m}$ from the patient, respectively [12]. Placing a surgical mask on the patient's face [13, 14] and using tightly fitting prongs [6] reduce exhaled air dispersion during HFNC. Also, clinicians should avoid placing an aerosol mask on top of HFNC to deliver aerosols with pressurized metered dose inhalers (pMDIs) or nebulizers because it decreases aerosol drug delivery via HFNC [15] due to physical obstruction/barrier created by the cannula. While some clinicians remove HFNC to use a facemask or mouthpiece for conventional aerosol therapy, the interruption of the HFNC therapy may have some clinical consequences such as the derecruitment of the lungs, the interruption of high flow inspired oxygen therapy and increased work of breathing in patients with COVID-19. To optimize aerosol delivery through HFNC, nebulizers should be placed before the humidifier [11, 16-18]. Thus, the rainout of larger particles will be drained in the humidifier that will lead 
TABLE 1

Suggestions for the delivery of aerosolized medications through HFNC safely and effectively in the era of COVID-19 and beyond.

\begin{tabular}{|c|c|c|}
\hline & Suggestions for effective aerosol delivery via HFNC & Suggestions for safe aerosol delivery via HFNC \\
\hline Nebulizer selection & $\begin{array}{l}\text { Prefer mesh nebulizers over jet nebulizers due to their greater } \\
\text { efficiency during HFNC therapy. }\end{array}$ & $\begin{array}{l}\text { Use an aseptic technique to prevent the contamination of the } \\
\text { nebulizer during device preparation. }\end{array}$ \\
\hline $\begin{array}{l}\text { Nebulizer placement } \\
\text { and use }\end{array}$ & $\begin{array}{l}\text { Place the mesh nebulizer at the inlet of the humidifier to } \\
\text { improve aerosol delivery through HFNC. }\end{array}$ & $\begin{array}{l}\text { Close the reservoir cap after use. } \\
\text { Clean the nebulizer based on the manufacturer's guidelines. }\end{array}$ \\
\hline HFNC cannula prongs & $\begin{array}{l}\text { Use larger HFNC cannulas but do not block more than } 50 \% \\
\text { of the cross-sectional area of each nostril. }\end{array}$ & $\begin{array}{l}\text { Make sure HFNC prongs are well fitted and not loose to reduce } \\
\text { the dispersion of bioaerosol during therapy. }\end{array}$ \\
\hline Gas flow & $\begin{array}{l}\text { Decrease flow rates during aerosol therapy, if it is tolerated } \\
\text { by the patient because aerosol drug delivery is inversely related } \\
\text { to gas flow. } \\
\text { Return the HFNC flow rate to the initial setting at the end of } \\
\text { the nebulization. }\end{array}$ & $\begin{array}{l}\text { Monitor patient to ensure that low flow rate is tolerated by the } \\
\text { patient. } \\
\text { Titrate gas flow based on patient's response to determine } \\
\text { optimum flow rate, if possible. } \\
\text { Titrate } \mathrm{FiO}_{2} \text { to maintain } \mathrm{SpO}_{2} \text { when using low flow rates for } \\
\text { aerosol therapy. }\end{array}$ \\
\hline Delivery technique & $\begin{array}{l}\text { Do not discontinue HFNC therapy for conventional aerosol } \\
\text { therapy. } \\
\text { Do not place an aerosol mask on top of HFNC to deliver } \\
\text { aerosols with pMDIs or nebulizers as it will decrease medication } \\
\text { delivery to the patient. }\end{array}$ & $\begin{array}{l}\text { Place a surgical mask on the face of the patient using HFNC to } \\
\text { minimize exhaled air dispersion and viral transmission. } \\
\text { Using an aerosol mask with a nebulizer on top of HFNC will } \\
\text { increase bioaerosol dispersion carrying pathogens. }\end{array}$ \\
\hline $\begin{array}{l}\text { Unit dose vs. continuous } \\
\text { nebulization with an } \\
\text { infusion pump }\end{array}$ & $\begin{array}{l}\text { Prefer unit dose to deliver aerosols. } \\
\text { Reduce gas flow during nebulization and return the flow rate } \\
\text { to initial settings after therapy. } \\
\text { Titrate } \mathrm{FiO}_{2} \text { to maintain } \mathrm{SpO}_{2} \text { during aerosol therapy. } \\
\text { Use a higher nominal dose with a low flow rate if continuous } \\
\text { nebulization with an infusion pump has to be used for } \\
\text { aerosol drug delivery. }\end{array}$ & $\begin{array}{l}\text { Place a surgical mask on the face of the patient using HFNC to } \\
\text { minimize exhaled air dispersion and viral transmission. } \\
\text { Monitor patient to ensure that low flow rate is tolerated by the } \\
\text { patient. } \\
\text { Titrate gas flow based on patient's response to determine } \\
\text { optimum flow rate, if possible. } \\
\text { Titrate } \mathrm{FiO}_{2} \text { to maintain } \mathrm{SpO}_{2} \text { when using low flow rates for } \\
\text { aerosol therapy. }\end{array}$ \\
\hline
\end{tabular}

Note: HFNC, high flow nasal cannula; pMDI, pressurized metered-dose inhaler.

to less condensation in the circuit. Placing the nebulizer before the humidifier will also keep aerosolized medications in the circuit during expiration as opposed to the position near the patient that will allow aerosol loss in expiration. Also, clinicians should avoid turning off the humidifier to increase aerosol drug delivery via HFNC because of patient discomfort and potential complications with the delivery of dry gas during therapy.

Although HFNC is designed to deliver higher gas flows than patients' inspiratory flow rates to avoid air entrainment during therapy, previous research showed an inverse relationship between HFNC flow rates and inhaled dose during quiet breathing [18-24]. Increasing flow rates reduce aerosol drug delivery via HFNC. While higher flow rates of HFNC increase both the turbulence and impactive loss of aerosolized medications, they also dilute aerosol within the stream of gas flowing to HFNC [11]. Previous research showed a 3 - to 12 -fold increase in aerosol drug delivery with lower HFNC flow rates [17, 22-25]. Also, the inhaled dose was higher when the HFNC flow rate was set below the patient's inspiratory flow rate $[17,26]$. Clinicians should consider setting HFNC gas flow $~ 50 \%$ of patient's inspiratory flow to increase aerosol drug delivery to patients with COVID-19, if tolerated by the patient. They should also monitor their patients closely during aerosol therapy and titrate the $\mathrm{HFNC}$ flow rate and $\mathrm{FiO}_{2}$ based on the patient's $\mathrm{SpO}_{2}$, tolerance, and response to the treatment.

Although jet and mesh nebulizers can be used for aerosol drug delivery through HFNC, previous research reported that mesh nebulizers offer 2-3 times higher inhaled doses than jet nebulizers [21, 22, 27] due to the low residual volume of drug remaining in the nebulizer cup after therapy. Since mesh nebulizers are operated by electricity, they may be more suitable for HFNC because they don't add extra gas flow to the system, unlike jet nebulizers. Also, aerosols can be delivered either intermittently via unit-dose or continuously using an infusion pump with HFNC. Aerosol deposition with the delivery of unit dose is higher than continuous nebulization with the HFNC infusion pump [25]. Clinicians should prefer using unit dose with HFNC and consider a higher nominal dose at low flow rates when using an infusion pump with HFNC. Patient monitoring during HFNC therapy, titrating gas flow based on patient's response to determine the optimum flow rate, and returning the flow rate to the initial settings after therapy is essential for safe and effective delivery of aerosols to patients with COVID-19.
One of the greatest threats of this pandemic is to properly control the spread of infection in hospitals. The general principles of infection control and prevention practices that emerged from previous literature are summarized below [3, 28].

- Assume all patients may be infected and use good personal protection during aerosol delivery in the era of COVID-19.

- Isolate patients and administer aerosolized medications in negative pressure rooms.

- Train your HCPs on infection control and prevention.

- Use personal protective equipment for aerosol and droplet protection.

- Adhere to airborne precautions during aerosol treatments for patients confirmed or suspected to be COVID-19 positive.

- Wash hands before and after each treatment

- Use an aseptic technique to avoid the contamination of nebulizer and medication.

- Maintain a distance of $1 \mathrm{~m}$ or more from the patient.

Future research

Although there are many in vitro studies on HFNC, the findings of previous in vitro studies need to be validated through future clinical studies. Studying the impact of aerosol delivery through HFNC on patient safety is warranted. Also, many factors such as the size and air exchange frequency of the room, the type of aerosol device used during therapy, and the movement of people in the room impact aerosol transmission. While previous in vitro studies evaluated some of these factors, more clinical research is needed to determine the impact of these factors on the transmission of bioaerosols in the era of COVID-19 and beyond.

\section{CONCLUSION}

The treatments of COVID-19 involve some degree of uncertainty. Current evidence shows mixed findings with regards to bioaerosol dispersion and airborne transmission of COVID-19 during HFNC therapy. While coping with this global pandemic created hot debates on the use of HFNC, it is important to bring detached opinions and current evidence to the attention of HCPs who may need to use HFNC in patients 
with COVID-19. This paper provides a framework on the selection, placement, and use of nebulizers as well as HFNC prongs, gas flow, and delivery technique via HFNC. When initiating HFNC therapy, clinicians should implement suggested strategies for safe and effective delivery of aerosolized medications through HFNC not only in the era of COVID-19 but also in the future.

\section{DISCLOSURES}

\section{Competing interest}

Dr. Ari discloses relationships with Aerogen Ltd and Philips Healthcare. Mr. Moody received unrestricted research grants from Aerogen Ltd.

\section{Funding}

No funding was obtained in the preparation of this editorial.

\section{Authors' contributions}

Dr. Ari conceived of the idea. Dr. Ari and Mr. Moody performed the literature search and drafted the editorial. All authors reviewed, revised, and approved the paper before submission.

\section{Ethics approval}

Not applicable.

\section{REFERENCES}

1. Agarwal A, Basmaji J, Muttalib F, et al. High-flow nasal cannula for acute hypoxemic respiratory failure in patients with COVID-19: systematic reviews of effectiveness and its risks of aerosolization, dispersion, and infection transmission. Can J Anaesth 2020;67:1217-48. doi: 10.1007/ s12630-020-01740-2.

2. Ari A, Fink JB. Recent advances in aerosol devices for the delivery of inhaled medications. Expert Opin Drug Deliv 2020;17:133-44. doi: $10.1080 / 17425247.2020 .1712356$.

3. Ari A. Practical strategies for a safe and effective delivery of aerosolized medications to patients with COVID-19. Respir Med 2020;167:105987. doi: 10.1016/j.rmed.2020.105987.

4. Ari A. Use of aerosolised medications at home for COVID-19. Lancet Respir Med 2020;8:754-6. doi: 10.1016/S2213-2600(20)30270-8.

5. Ari A. Promoting safe and effective use of aerosol devices in COVID-19: risks and suggestions for viral transmission. Expert Opin Drug Deliv 2020;17:1509-13. doi: 10.1080/17425247.2020.1811225.

6. Hui D, Chow B, Lo T, et al. Exhaled air dispersion during high-flow nasal cannula therapy versus CPAP via different masks. Eur Respir J 2019;53:1802339. doi: 10.1183/13993003.02339-2018.

7. Ip M, Tang JW, Hui DS, et al. Airflow and droplet spreading around oxygen masks: a simulation model for infection control research. Am J Infect Control 2007;35:684-9. doi: 10.1016/j.ajic.2007.05.007.

8. Leung C, Joynt G, Gomersall C, et al. Comparison of high-flow nasal cannula versus oxygen face mask for environmental bacterial contamination in critically ill pneumonia patients: a randomized controlled crossover trial. J Hosp Infect 2019;101:84-7. doi: 10.1016/j.jhin.2018.10.007.

9. Kotoda M, Hishiyama S, Mitsui K, et al. Assessment of the potential for pathogen dispersal during high-flow nasal therapy. J Hosp Infect 2020;104:534-7. doi: 10.1016/j.jhin.2019.11.010.

10. van Doremalen N, Bushmaker T, Morris D, et al. Aerosol and surface stability of SARS-CoV-2 as compared with SARS-CoV-1. New Engl J Med 2020;NEJMc2004973. doi: 10.1101/2020.03.09.20033217.

11. Ari A. Aerosol drug delivery through high flow nasal cannula. Curr Pharm Biotechnol 2017;18:877-82. doi: 10.2174/1389201019666171219104217.
12. McGrath J, O’Toole C, Bennett G, Joyce M, Byrne M, MacLoughlin R. Investigation of fugitive aerosols released into the environment during high-flow therapy. Pharmaceutics 2019;11:254. doi: 10.3390/ pharmaceutics 11060254.

13. Leonard S, Atwood CW Jr., Walsh BK, et al. Preliminary findings on control of dispersion of aerosols and droplets during high-velocity nasal insufflation therapy using a simple surgical mask: implications for the high-flow nasal cannula. Chest 2020;158:1046-9. doi: 10.1016/j. chest.2020.03.043.

14. Li J, Fink J, Elshafei A, et al. Placing a mask on COVID-19 patients during high flow nasal cannula therapy reduces aerosol particle dispersion. ERJ Open Res 2021;7(1);519-2020. doi: 10.1183/23120541.00519-2020.

15. Alalwan MA, Fink JB, Ari A. In vitro evaluation of aerosol drug delivery with and without high flow nasal cannula in children. Pediatr Pulmonol 2019;54:1968-73. doi: 10.1002/ppul.24501.

16. Sunbul FS, Fink JB, Harwood R, Sheard MM, Zimmerman RD, Ari A. Comparison of HFNC, bubble CPAP and SiPAP on aerosol delivery in neonates: an in-vitro study. Pediatr Pulmonol 2015;50:1099-106. doi: 10.1002/ppul.23123.

17. Li J, Gong L, Ari A, Fink JB. Decrease the flow setting to improve trans-nasal pulmonary aerosol delivery via "high-flow nasal cannula" to infants and toddlers. Pediatr Pulmonol 2019;54:914-21. doi: 10.1002/ ppul.24274.

18. Réminiac F, Vecellio L, Heuzé-Vourc'h N, Petitcollin A, Respaud R, Cabrera M. Aerosol therapy in adults receiving high flow nasal cannula oxygen therapy. J Aerosol Med Pulm Drug Deliv 2016;29:134-41. doi: 10.1089/jamp.2015.1219.

19. Ari A, Harwood R, Sheard M, Dailey P, Fink JB. In vitro comparison of heliox and oxygen in aerosol delivery using pediatric high flow nasal cannula. Pediatr Pulmonol 2011;46:795-801. doi: 10.1002/ppul.21421.

20. Dailey PA, Harwood R, Walsh K, et al. Aerosol delivery through adult high flow nasal cannula with heliox and oxygen. Respir Care 2017;62:1186-92. doi: 10.4187/respcare.05127.

21. Ari A. Effect of nebulizer type, delivery interface, and flow rate on aerosol drug delivery to spontaneously breathing pediatric and infant lung models. Pediatr Pulmonol 2019;54:1735-41. doi: 10.1002/ppul.24449.

22. Reminiac F, Vecellio L, Loughlin RM, et al. Nasal high flow nebulization in infants and toddlers: an in vitro and in vivo scintigraphic study. Pediatr Pulmonol 2017;52:337-44. doi: 10.1002/ppul.23509.

23. Corcoran TE, Saville A, Adams PS, et al. Deposition studies of aerosol delivery by nasal cannula to infants. Pediatr Pulmonol 2019;54:1319-25. doi: $10.1002 /$ ppul.24326.

24. Alcoforado L, Ari A, Barcelar JM, Brandão SCS, Fink JB, de Andrade AD. Impact of gas flow and humidity on trans-nasal aerosol deposition via nasal cannula in adults: a randomized cross-over study. Pharmaceutics 2019;11(7):320. doi: 10.3390/pharmaceutics 11070320 .

25. Li J, Wei W, Fink JB. In vitro comparison of unit dose vs infusion pump administration of albuterol via high-flow nasal cannula in toddlers. Pediatr Pulmonol 2020;55:322-9. doi: 10.1002/ppul.24589.

26. Li J, Gong L, Fink JB. The ratio of nasal cannula gas flow to patient inspiratory flow on trans-nasal pulmonary aerosol delivery for adults: an in vitro study. Pharmaceutics 2019;11(5):225. doi: 10.3390/ pharmaceutics 11050225.

27. Dugernier J, Hesse M, Jumetz T, et al. Aerosol delivery with two nebulizers through high-flow nasal cannula: a randomized cross-over single-photon emission computed tomography-computed tomography study. J Aerosol Med Pulm Drug Deliv 2017;30:349-58. doi: 10.1089/ jamp.2017.1366.

28. Fink J, Ehrmann S, Li J, et al. Reducing aerosol-related risk of transmission in the era of COVID-19: an interim guidance endorsed by the International Society of Aerosols in medicine. J Aerosol Med Pulm Drug Deliv 2020;33(6):300-4. doi: 10.1089/jamp.2020.1615. 